\title{
Topical issue “Plasma Sources and Plasma Processes (PSPP)”
}

The present Special Issue of the European Physical Journal - Applied Physics (EPJ-AP), on Plasma Sources and Plasma Processes, corresponds to a selection of papers, after regular peer-review, from the $\mathbf{2 1}^{\text {st }}$ International Colloquium on Plasma processes (CIP) jointly with the $5^{\text {th }}$ Magnetron Ion processing \& Arc Technologies European Conference (MIATEC), that were hold from 26 to 30 June 2017, in Nice, France.

The papers cover both applied topics (the synthesis of ultra-light-density metallic foams for laser experiments and the nonlinear properties of very-thick mixture-oxide ion beam sputtering films), as well as fundamental studies in support of applications (the modelling of a large-area distributed-antenna-array microwave-plasma reactor for nanocrystalline diamond deposition). Several papers are dedicated to the study of active species and fundamental mechanisms (e.g., electron-ion recombination and the catalytic effect of impurities in the thermal desorption of thin films) in $\mathrm{N}_{2}, \mathrm{H}_{2}$ and $\mathrm{D}_{2}$ (and mixtures) low-temperature plasmas and afterglows.

As Associated and Guest Editors of the EPJ-AP for this Special Issue, we would like to thank all the authors and referees for their efforts in preparing and reviewing the manuscripts, within very strict deadlines, as well as the Editorial Office of the EPJ-AP for its helpful organizational assistance. We would like very much to extend our gratitude to all the participants of CIP and MIATEC. When decision was made to jointly hold these conferences in Nice, France, under the sun of the French Riviera, we could not imagine that this place would be chosen by a bunch of terrorists to drive a 19 tonne cargo truck deliberately into crowds of people celebrating Bastille Day on the Promenade des Anglais. That was the very moment when invitations to speakers should have been sent. The organizers postponed it by 2 months, but the idea of organizing the event elsewhere never crossed their minds. Finally, the 2017 edition of these conferences was a success, with 136 participants from more than 20 countries.

This was the last edition of the biennial international conferences, CIP and MIATEC, in the present format. CIP and MIATEC, together with the international conference on Innovations in Thin Film Processing and Characterization (ITFPC'17), a biennial conference that was held for the very last time on October 23-27, 2017, in Nancy, France, will merge to create a new conference: PLATHINIUM (Plasma Thin film International Union Meeting), to be organized also under the auspices of the French Vacuum Society.

The first edition of PLATHINIUM will be held from 23 to 29 September 2019, in Antibes, France. All are welcome.

Luís Lemos ALVES Thierry BELMONTE Tiberiu MINEA 